\title{
ID4 controls luminal lineage commitment in normal mammary epithelium and inhibits BRCA1 function in basal-like breast cancer
}

\author{
Laura A Baker1,2, Holly Holliday ${ }^{1,2}$ and Alexander Swarbrick1,2 \\ 1The Kinghorn Cancer Centre and Cancer Research Division, Garvan Institute of Medical Research, \\ Darlinghurst, New South Wales, Australia \\ ${ }^{2}$ St Vincent's Clinical School, Faculty of Medicine, University of New South Wales, Sydney, \\ New South Wales, Australia
}

Correspondence should be addressed

to A Swarbrick

Email

a.swarbrick@garvan.org.au

\begin{abstract}
Inhibitor of differentiation (ID) proteins are key regulators of development and tumorigenesis. One member of this family, ID4, controls lineage commitment during mammary gland development by acting upstream of key developmental pathways. Recent evidence suggests an emerging role for ID4 as a lineage-dependent protooncogene that is overexpressed and amplified in a subset of basal-like breast cancers (BLBCs), conferring poor prognosis. Several lines of evidence suggest ID4 may suppress $B R C A 1$ function in BLBC and in doing so, define a subset of BLBC patients who may respond to therapies traditionally used in $B R C A 1$-mutant cancers. This review highlights recent advances in our understanding of the requirement for ID4 in mammary lineage commitment and the role for ID4 in BLBC. We address current shortfalls in this field and identify important areas of future research.
\end{abstract}

\section{Key Words}

- basal-like breast cancer

- ID4

- inhibitor of differentiation 4

- BRCA1

- lineage dependent oncogene

\section{Introduction}

Inhibitor of differentiation (ID) proteins are a family of four (ID1-4) helix-loop-helix (HLH) transcriptional regulators. They demonstrate distinct tissue-specific expression patterns and regulate various cell processes including transcription, differentiation and cell cycle progression. Recent reviews have eloquently addressed the biological requirement for ID proteins (Lasorella et al. 2014, Nair et al. 2014). In recent years, we have gained insight into the role of one member of this family, ID4, in mammary gland development and tumorigenesis.

\section{ID4 controls mammary epithelial cell lineages}

The mammary gland as a model of epithelial stem cell biology

Mammary gland development is almost exclusively postnatal (reviewed in Watson and Khaled 2008). As such, it is a particularly unique model for studying epithelial stem cell biology and differentiation. Murine models are often used to study the mammary gland as these developmental processes are highly conserved with humans. The pubertal mammary 
gland is characterised by a branching ductal structure culminating in terminal end buds (TEBs). The cap cells residing at the ends of these TEBs are characterised by high proliferation and stem/progenitor activity (Williams \& Daniel 1983, Bai \& Rohrschneider 2010). These cells drive invasive ductal branching through the mammary fat pad during puberty.

The mammary gland is continually remodelled as a result of external hormonal (de Candia et al. 2006) and growth factor signals (Bouras et al. 2008, Li et al. 2008). These cues result in expansion of the stem/progenitor cell population during puberty and differentiation during pregnancy and lactation. The resulting bilayered ducts are comprised predominantly of two terminally differentiated cell types, the inner luminal cell layer and the surrounding basal/myoepithelial cell layer, which are enriched for mammary stem cell activity (MaSC) (Williams \& Daniel 1983, Best et al. 2014, Junankar et al. 2015). Cells of this basal layer will henceforth be referred to as basal cells.

Terminally differentiated mammary cell lineages can be characterised by distinct molecular signatures (Lim et al. 2009), coordinated by the activity of several transcription factors. A number of transcriptional regulators required for terminal differentiation of the mammary gland are breast cancer type-1 susceptibility protein (BRCA1), E74like factor 5 (ELF5), GATA-binding protein 3 (GATA3) and Forkhead box protein M1 (FOXM1). Combined with alterations to Notch signalling, these factors affect luminal progenitor differentiation and terminal differentiation of ductal/alveolar luminal cells (Kouros-Mehr et al. 2006, Liu et al. 2008, Oakes et al. 2008, Carr et al. 2012). In contrast, the transcriptional mediators of basal cell differentiation are relatively poorly understood. This is partially a result of difficulties in the purification and molecular and biochemical characterisation of these cells (Lindvall et al. 2006, Zeng \& Nusse 2010).

\section{ID4 in the mammary gland}

Increasing evidence supports a central role for ID4 in regulating mammary cell proliferation and lineage commitment. Lim and coworkers (Lim et al. 2009, Lim et al. 2010) purified and analysed the transcriptional signatures of the main cell populations comprising the mammary gland: luminal progenitors (LPs), committed/ mature luminal (ML) and basal cells. Comparison of the basal population with either the LP or ML cells revealed differential expression of many genes. Amongst them,
ID4 was one of the highest differentially expressed genes specific to basal cells of both human and murine origin (Lim et al. 2009, 2010).

Research by Junankar and coworkers and Best and coworkers (Junankar et al. 2015, Best et al. 2014) has subsequently shown almost exclusive localisation of ID4 within the basal cell compartment, particularly within the cap cells of the TEBs (Williams \& Daniel 1983). Interestingly, a small proportion of luminal progenitor cells have also been reported to express ID4 during pubertal development (Best et al. 2014). ID4 controls luminal commitment and mammary stem/progenitor cell self-renewal by acting as a negative regulator of several key pathways involved in luminal fate specification, namely Notch signalling, BRCA1, ELF5, ER $\alpha$ and FOXA1 (Best et al. 2014, Junankar et al. 2015). The ID4-mediated inhibition of ELF5 occurs indirectly via Notch signalling (Junankar et al. 2015), while ID4 has been shown to inhibit ER $\alpha, F O X A 1$ and BRCA1 expression by direct interaction with the promoters of these genes (Beger et al. 2001, Best et al. 2014). As ID4 does not have a basic DNA-binding domain (reviewed in Sharma et al. 2015), it is likely that it regulates gene expression by forming a complex with other transcriptional regulators. The identity of these transcriptional regulators is currently unknown. Loss-of-function studies have confirmed the requirement for ID4 in ductal morphogenesis in the developing pubertal mammary gland (Dong et al. 2011, Best et al. 2014, Junankar et al. 2015), with ID4-positive cells repopulating the adult mammary gland at a greater frequency than ID4-negative cells demonstrating the intrinsic stem cell activity of the ID4-positive basal cells (Junankar et al. 2015). ID4-knockout mice also have delayed ductal morphogenesis further signifying the requirement for this transcription factor in mammary gland development (Dong et al. 2011, Junankar et al. 2015).

\section{ID4 interacts with important developmental regulators ER $\alpha$ and $B R C A 1$}

\section{ID4, ER $\alpha$ and BRCA1 in the mammary gland}

Transcriptional regulation of mammary gland development has been broadly studied. ER $\alpha$, for example, is a key controller of cell proliferation during mammary gland development (Korach et al. 1995, Feng et al. 2007). Depletion of ER $\alpha$ or disruption of its signalling network results in the formation of rudimentary mammary gland structures (Korach et al. 1995, Mallepell et al. 2006).

Published by Bioscientifica Ltd. 
Similarly, ID4 is expressed in hormonally regulated tissues including the breast, ovaries and prostate and is required for normal development (Shan et al. 2003, Dong et al. 2011, Sharma et al. 2013, Best et al. 2014, Junankar et al. 2015). ID4 is stimulated by progesterone receptor (PR) activity through direct binding of ligand-activated PR to the ID4 promoter (Fernandez-Valdivia et al. 2008). Mammary ID4 expression fluctuates through the oestrous cycle (S Junankar and A Swarbrick, unpublished observations) and murine ID4-knockout models show impaired production of oestradiol synthesis enzymes (Best et al. 2014). Other studies identify $\beta$-oestradiol as an inhibitor of ID4 expression (Beger et al. 2001), suggesting a complex regulatory interaction role between ID4 and $\mathrm{ER} \alpha$ that remains to be fully elucidated.

Conversely, Best and coworkers suggest that ID4 inhibits the expression of both ER $\alpha$ and its cofactor FOXA1 in the developing mammary gland (Best et al. 2014). This occurs through interaction of ID4 with the promoters of these genes. When ID4 is depleted, ERo expression is reactivated in the myoepithelial and luminal progenitor compartments, cell populations that do not express ER $\alpha$ under normal conditions (Best et al. 2014). This correlates with data showing almost exclusive localisation of ID4 expression to the ER $\alpha$-negative basal cell compartment (de Candia et al. 2006, Junankar et al. 2015). These findings have led many researchers to hypothesise that ER $\alpha$ signalling inhibits ID4 in the developing mammary gland and loss of ID4 may be an early event in the formation of ID4-negative ER $\alpha$-positive breast cancer (Beger et al. 2001, de Candia et al. 2006, Junankar et al. 2015).

BRCA1, a regulator of mammary stem cell fate, is required for the differentiation of basal cells into luminal cells (Liu et al. 2008). BRCA1 depletion results in blocked epithelial differentiation (Liu et al. 2008). Negative regulation of BRCA1 by ID4 is one of the mechanisms through which ID4 maintains the basal population (Junankar et al. 2015).

\section{ID4, ER $\alpha$ and BRCA1 in breast cancer}

ID4, ER $\alpha$ and BRCA1 have been studied for their roles in normal breast development and cancer. BRCA1, the breast and ovarian cancer susceptibility gene, is responsible for the majority of hereditary breast cancer cases ((Lakhani et al. 2005, Turner et al. 2007) and reviewed in Mavaddat et al. 2010). BRCA1 and ER $\alpha$ mRNA expression have been shown to correlate in sporadic breast cancers (Roldán et al. 2006), while ID4 is negatively correlated to both
BRCA1 and ERa (Roldán et al. 2006, Thike et al. 2015). This phenomenon has been suggested to occur through ERo inhibition of ID4 in a luminal breast cancer cell line (Beger et al. 2001). However, the relevance is unclear, as in clinical breast cancer, ID4 expression is exclusive to ER $\alpha$ negative subtypes of breast cancer (Crippa et al. 2014). This evidence has led researchers to suggest that ID4 loss may be important in the development of ER $\alpha$-dependent breast cancers (de Candia et al. 2006), and conversely, ID4 may suppress BRCA1 and ER $\alpha$ in ID4-positive BLBC (Best et al. 2014), resulting in poor survival outcomes (Junankar et al. 2015, Thike et al. 2015).

Furthermore, ID4 depletion in a basal-like MMTV-Wnt-1 mammary tumour model results in re-expression of ER $\alpha$ and activation of the ER $\alpha$ signalling network, indicated by the expression of FOXA1 (Best et al. 2014). This data suggest that by inhibiting ID4 in BLBC, we may be able to reactivate luminal pathways, potentially rendering them susceptible to hormonal therapies such as $\mathrm{ER} \alpha$ inhibition. Testing in more BLBC models is required to confirm these findings and to determine their clinical ramifications.

\section{Cell of origin}

Our understanding of the normal cells from which cancer originates is incomplete. In recent years, we have begun to identify the molecular and cellular characteristics that must be acquired to enable malignant transformation. Gain of proliferative and angiogenic capacity, resistance to tumour suppression and cell death as well as acquired invasive and metastatic potential are well-established hallmarks of cancer (Hanahan \& Weinberg 2011). However, it is unclear which cells are primed to acquire these advantages and whether the cell of origin predisposes patients to particular disease aetiologies.

Increasing evidence suggests that cancer phenotype is in part dictated by the cell of origin ((Barker et al. 2009) and reviewed in Visvader 2009). Lineage tracing experiments have demonstrated the role of unipotent and multi-potent stem cells in maintaining epithelial tissue through the generation of terminally differentiated cell types (Shackleton et al. 2006, Stingl et al. 2006, Barker et al. 2009, Van Keymeulen et al. 2011, Rios et al. 2014, Wang et al. 2015). By identifying the cell of origin, we will be able to examine, with greater precision, the molecular and biological changes enabling cancer initiation and progression and identify targeted approaches to treat cancers in early development. 


\section{Cell of origin in BLBC}

Breast cancer is a heterogeneous disease that can be stratified into at least five major subtypes: luminal A, luminal B, Her2-enriched, basal-like and normal-like (Perou et al. 2000). Each has unique molecular and genomic features and histopathology that effect different clinical outcomes (Prat \& Perou 2011). Basal-like breast cancer (BLBC) is a poorly characterised, heterogeneous disease that accounts for $\sim 18 \%$ of all breast cancer diagnoses (Sørlie et al. 2001, Prat \& Perou 2011, Cancer Genome Atlas Network 2012). Patients are diagnosed at an earlier age than other subtypes, with aggressive, high-grade tumours and often relapse with chemotherapy resistance.

The BLBC subtype is enriched for patients harbouring mutations in tumour suppressor protein 53 (TP53) and BRCA1 ((Lakhani et al. 2005, Turner et al. 2007, Bertheau et al. 2013) and reviewed in Mavaddat et al. 2010). This subtype has been defined using molecular analysis of patient samples and represents a subset of the triplenegative subtype. This has been extensively reviewed in recent years (Badve et al. 2011, Prat et al. 2013). BLBCs generally lack expression of ER $\alpha$, PR and human epidermal growth factor receptor 2 (Her2) and are marked by the presence of cytokeratin 5/6 and/or epidermal growth factor receptor (EGFR). Patients are unsuitable for currently available targeted therapeutics (Perou et al. 2000, Sørlie et al. 2001). This contributes to the poor survival associated with this disease, which is compounded by considerable molecular and clinical heterogeneities. Approximately, $30-50 \%$ of patients relapse within 3-5 years, while the remaining patients have good longterm survival (reviewed in Rakha et al. 2008). Effective stratification of patients through predictive biomarker discovery is crucial to improving treatment options and patient survival, as is the discovery of new therapeutic vulnerabilities in BLBC.

Basal cytokeratins are highly expressed in BLBC ((Prat et al. 2013) and reviewed in Gusterson et al. 2005). Accordingly, initial research suggested that mammary stem (MaSC) or basal cells were the possible cells of origin for BLBCs. In support of this hypothesis, BRCA1 depletion blocks epithelial differentiation, as mentioned above (Liu et al. 2008), and increases the population of genetically unstable stem/progenitor cells, a known predisposing event to the formation of BLBC ((Miki et al. 1994, Liu et al. 2008) and reviewed in Turner et al. 2007).

The origination of BLBC from the MaSC population is also supported by study of ID4 in the transformation process. ID4 is localised to the basal cell compartment in the normal breast, and high ID4-expressing cells from a murine cell line possess upregulation of MaSC-associated genes (Junankar et al. 2015). Furthermore, human BLBCs with high ID4 expression closely resemble the MaSC molecular signature (Junankar et al. 2015), suggesting that ID4 may play an important role in progression from normal MaSCs to BLBC.

Conversely, recent studies have hypothesised LPs as the cell of origin for BLBCs (Lim et al. 2009, Molyneux et al. 2010). To uncover the cell of origin, Lim and coworkers (2009) used microarray analysis to investigate the gene expression signatures of sorted mammary populations: basal, luminal progenitor (LP) and mature luminal (ML) cells (Lim et al. 2009). These were compared with preneoplastic normal breast tissue from patients with BRCA1 mutations and with the different breast cancer subtypes. High similarity was observed between the LP population and BRCA1-mutant pre-neoplastic tissue. Furthermore, when compared with different breast cancer subtypes, the LP population most closely resembled the BLBC subtype. Comparative analysis of BRCA1 wild-type and mutant patients demonstrated an expansion of the LP population in the BRCA1-mutant cases (Lim et al. 2009). Taken together, these findings suggest that the LP is the precursor for BRCA1-mutant BLBC. Though Lim and coworkers do not provide direct evidence that BLBCs originate from the LP population, Molyneux and coworkers (2010) have subsequently directed BRCA1 depletion to either predominantly the basal (consisting of basal stem cells) or luminal (consisting of LP cells) mammary epithelial cells, and showed that both conditions resulted in the formation of tumours that possessed molecular features resembling BLBC. However, only the tumours resulting from BRCA1depleted luminal progenitor cells recapitulated the histological features of BLBC (Molyneux et al. 2010). BRCA1 loss in basal cells instead generated malignant adenomyoepitheliomas, a rare breast cancer known to originate from stem cells (Molyneux et al. 2010).

Though the above evidence appears to support two opposing hypotheses, the weight of evidence suggests that BLBCs originate from the LP population, potentially from the small proportion of ID4-positive LP cells (Best et al. 2014), and a proportion of these tumours de-differentiate to acquire MaSC-like features (Fig. 1). This plasticity during transformation has been described in BLBC previously (Chaffer et al. 2013) and has been recently reviewed (Blanpain \& Fuchs 2014).

As described above, ID4 expression is high in the basal population and low in the LP population (Fig. 1) 


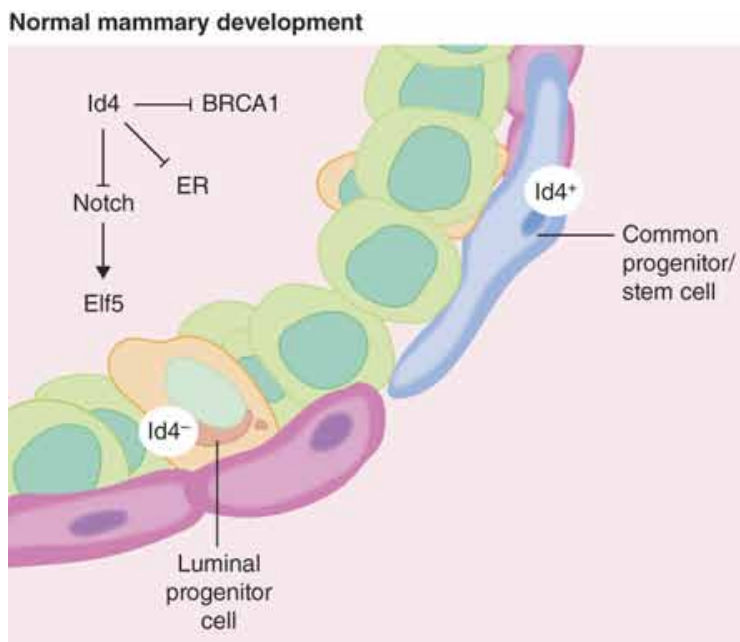

Mammary transformation

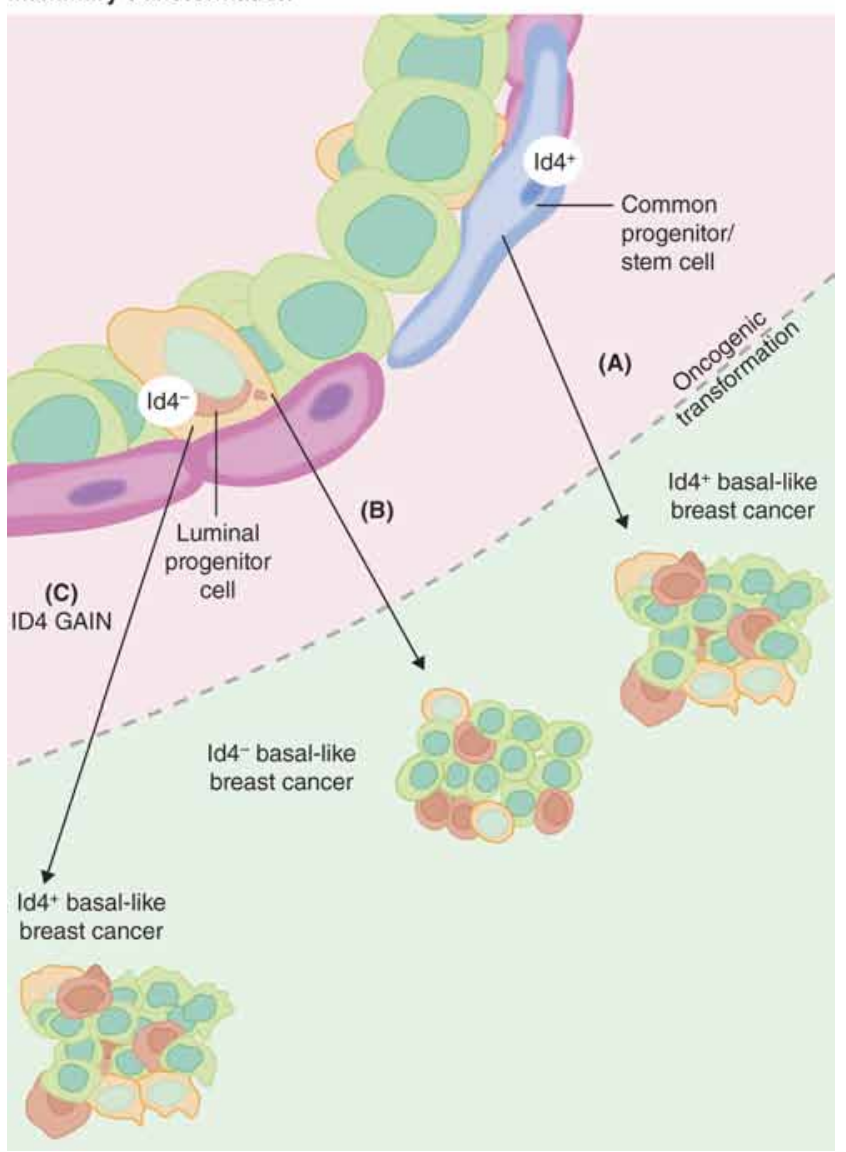

Figure 1

Cell of origin for ID4 $\pm B L B C$. (1) ID4 controls lineage commitment in the developing mammary gland through regulation of key lineage commitment genes Notch, ER, ELF5 and BRCA1. (2) Sophisticated murine models and clinical data suggest that transformation of normal mammary cells may occur through three pathways: (A) ID4+ common progenitor/stem cells may give rise to ID4+ basal-like breast cancers. This idea largely originates from molecular analysis of patient samples, where ID4+ BLBCs possess transcriptional signatures resembling mammary stem cells (Junankar et al. 2015). (B and C) ID4- luminal progenitors may form
(Lim et al. 2009, Molyneux et al. 2010, Junankar et al. 2015). We propose that ID4-positive BLBCs originate from LP cells, and gain ID4 expression and gene amplification (Turner et al. 2004, Molyneux et al. 2010). This results in de-differentiation to an MaSC-like state resulting in similarities between the BLBC and MaSC transcriptomes (Junankar et al. 2015). The genetic alterations acquired during malignant transformation may account for the gene expression heterogeneity marking the ID4-positive BLBC compared with the ID4-negative BLBC (Junankar et al. 2015). This has implications for diversity in response to therapy and clinical outcome that is observed in BLBC.

\section{ID4: a lineage-dependent oncogene in basal-like breast cancer}

\section{Development gone awry}

Elucidating the role of key transcriptional regulators and lineage fate commitment genes has enabled incredible insight into tumorigenesis. Regulators of lineage commitment often become deregulated during transformation, driving tumour growth and progression. These factors are termed lineage-dependent oncogenes (reviewed in Garraway and Sellers 2006). As such, by exploiting these oncogene dependencies, we may uncover new therapeutic targets. Several transcription factors controlling luminal lineage commitment, such as GATA3 and BRCA1, are potent breast tumour suppressors that are aberrantly expressed or mutated in breast cancer (Kouros-Mehr et al. 2006, Asselin-Labat et al. 2007, Chen et al. 2010, Carr et al. 2012). Parallel to the developmental importance of $E R \alpha$, as described above, researchers have shown increased levels of ER $\alpha$ in the benign breast

either ID4- or ID4+ BLBC. Molecular comparison of luminal progenitors with breast cancer subtypes reveals close association with the BLBC subtype. However, analysis of this mixed basal-like subtype (including ID4- and ID4+ tumours) may complicate the findings. We hypothesise that the luminal progenitor population gives rise to ID4- and ID4+ BLBC, the ID4- BLBC resembling the luminal progenitors and the ID4+ BLBC resembling a de-differentiated mammary stem cell signature. We are currently unable to distinguish the ID4+ BLBC derived from luminal progenitors with the transformation events occurring in $(A)$. It has been shown that transformation seen in $(A)$ and $(C)$ results in more aggressive, poorly differentiated tumours (Junankar et al. 2015). In (C), ID4 is gained through unknown mechanisms. Evidence gathered from murine models identifies BRCA1 mutation in luminal progenitor cells as the predisposing event to the formation of ID4+ BLBCs. Similarly, clinical data identify preferential ID4 amplification in BRCA1-mutant cases (Prat et al. 2014), suggesting an advantage to ID4 gain in tumorigenesis. Conversely, BRCA1 mutation in common progenitor/stem cells results in the formation of ID4-positive adenomyoepitheliomas, a rare malignancy (Molyneux et al. 2010). ID4+, ID4-positive; ID4-, ID4-negative.

Published by Bioscientifica Ltd. 


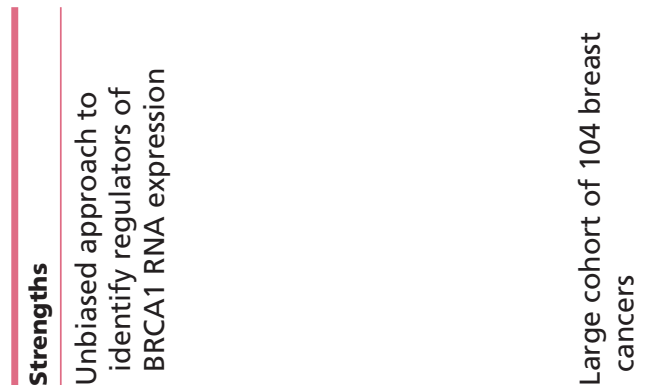

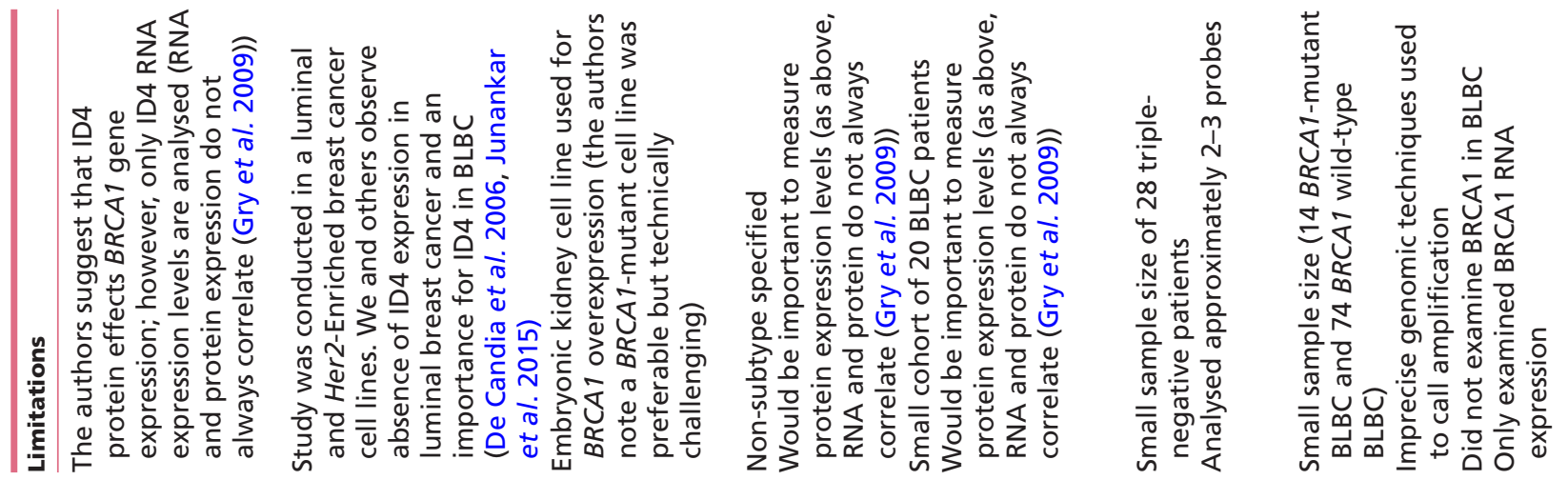
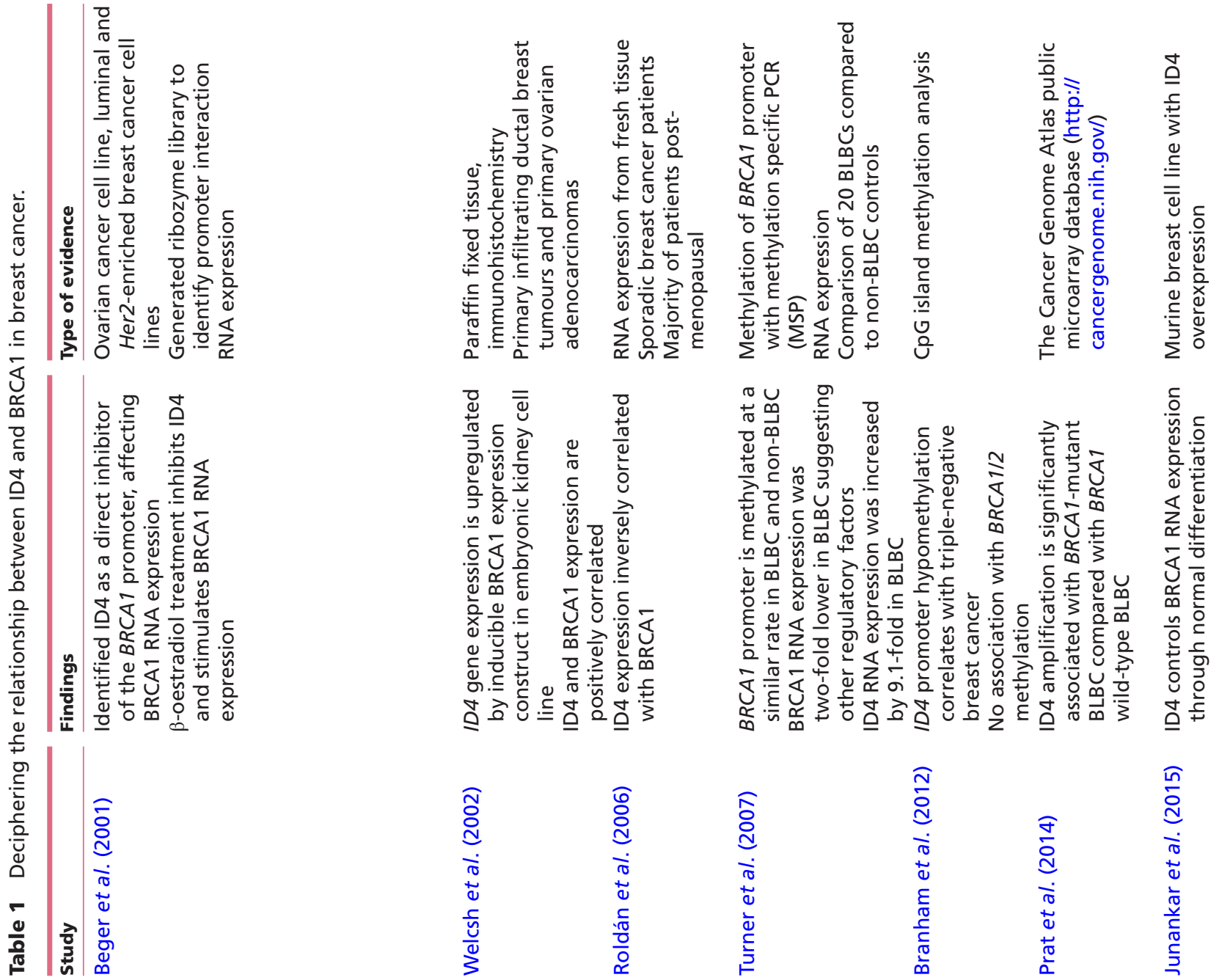
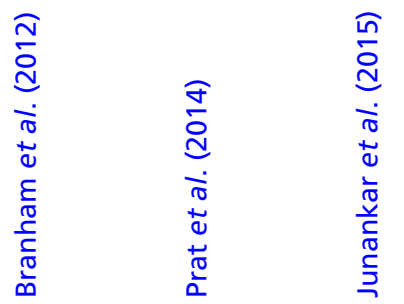


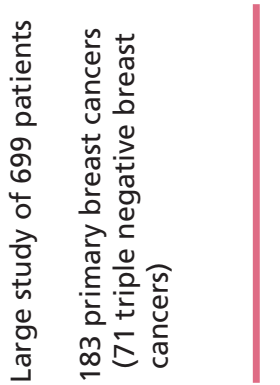

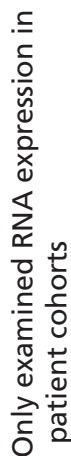
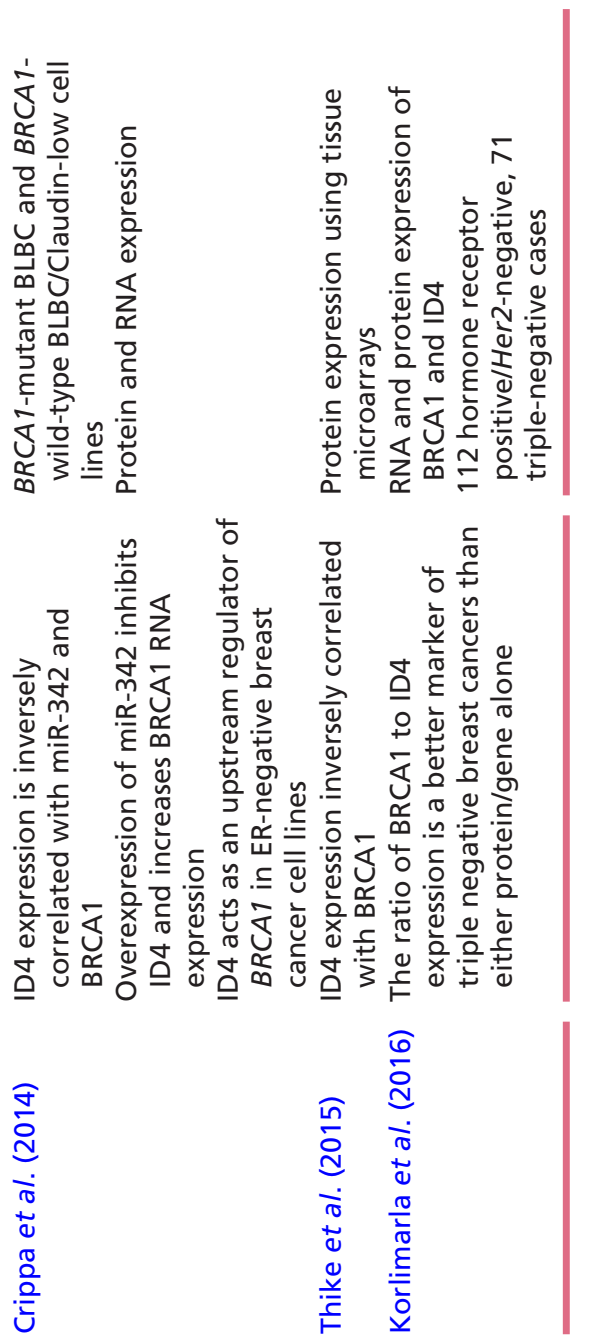

C 2016 Society for Endocrinology Printed in Great Britain epithelium predisposes women to develop breast cancer (Khan et al. 1998). This gene controls the growth of luminal subtypes, accounting for $\sim 70 \%$ of all breast cancers (reviewed in Lumachi et al. 2015). The requirement for ER $\alpha$ in the development and progression of these cancers is well established, and specific drug targeting of ER $\alpha$ has led to improved survival in breast cancer patients over the last 30 years (reviewed in Lumachi et al. 2015).

\section{ID4 controls malignancy in BLBC}

In contrast, the lineage dependencies of BLBC are poorly understood. Due to the developmental requirement for ID4, researchers hypothesised that ID4 may function in tumorigenesis. Studies focused on the importance of this protein in breast cancer have produced varied, complex results as a consequence of different models, technical approaches and experimental designs. As such, debate regarding the precise function of ID4 continues. ID4 effects varied outcomes in cell proliferation and differentiation depending on the availability of cofactors, and hence, play either a tumour suppressive or oncogenic function.

ID4 acts as a tumour suppressor, for example, in the normal prostate where it is highly expressed; this expression decreases in prostate cancer in a stage-dependent manner as a result of ID4 promoter hypermethylation (Carey et al. 2009, Sharma et al. 2012). High-grade tumours are associated with the absence of ID4 expression (Carey et al. 2009, Sharma et al. 2012). In this context, ID4 exerts anti-proliferative effects, in part, by increasing expression of the classical tumour suppressor genes p27 and p21 (Carey et al. 2009). This work highlights the divergent and context-dependent roles of ID4 in different hormone-dependent cancers.

There is now convincing evidence that ID4 is a protooncogene in BLBC. This subtype is associated with ID4 overexpression and amplification (de Candia et al. 2006, Turner et al. 2007, Natrajan et al. 2010). In BLBC, ID4 correlates with TP53 protein expression which associates with higher grade and risk of metastasis (Thike et al. 2015). ID4 is required for the proliferation of BLBC cell lines in vitro and in vivo and marks a subset of poor prognosis BLBCs (Junankar et al. 2015, Valenti et al. 2015).

\section{ID4 and BRCA1 in BLBC}

The relationship between ID4 and BRCA1 is poorly understood. The majority of the literature is based on

Published by Bioscientifica Ltd. 
correlative data; however, emerging evidence is beginning to identify a fundamental genetic requirement for this interaction. The literature surrounding ID4 and BRCA1 is summarised in Table 1. ID4 and BRCA1 expression are inversely correlated in sporadic BLBC (Turner et al. 2007, Thike et al. 2015, Korlimarla et al. 2016). Beger and coworkers (2001) subsequently characterised the regulators of $B R C A 1$ gene expression and identified ID4 as an upstream regulator of the $B R C A 1$ promoter using an inverse genomics approach in luminal breast cancer cell lines. However, our research, and that from other laboratories, has shown exclusive ID4 protein expression in the ER $\alpha$-negative subtypes of breast cancer, particularly BLBC where it is believed ID4 plays a crucial role in aetiology of this disease (de Candia et al. 2006, Roldán et al. 2006, Wen et al. 2012, Best et al. 2014, Junankar et al. 2015). Importantly, the inhibitory effect of ID4 on BRCA1 has since been confirmed in ER $\alpha$-negative breast cancer cell lines (Crippa et al. 2014).

Further to ID4 directly controlling BRCA1 gene expression, BRCA1 has been shown to reciprocally induce ID4 in normal kidney cells (Welcsh et al. 2002). It is currently unclear whether BRCA1 directly interacts with the ID4 promoter or whether this regulation occurs through other signalling pathways such as ERo. BRCA1 has been shown to inhibit ER $\alpha$ activity and activate transcription through the transcriptional regulator p300 ((Fan et al. 1999), reviewed in Mullan et al. 2006). However, it is unclear how this may affect the regulation of ID4 in malignant breast tissue where ER $\alpha$ and BRCA1 expression is correlated (de Candia et al. 2006, Roldán et al. 2006). This suggests that ID4 may be exerting similar inhibitory effects on BRCA1 and ER $\alpha$, and conversely that BRCA1 and ER $\alpha$ may demonstrate redundancy in inhibiting ID4.

Combined with the data above, this suggests that BRCA1 and ID4 are involved in a regulatory loop, which in normal cells maintains homeostasis: ID4 inducing proliferation and inhibiting differentiation (Shan et al. 2003, Fontemaggi et al. 2009) and BRCA1 promoting differentiation and preventing proliferation (Furuta et al. 2005). Supporting this model, depletion or mutation of BRCA1 in mouse models results in the formation of aggressive tumours molecularly resembling BLBCs that interestingly express high levels of ID4 (Molyneux et al. 2010). Additionally, ID4 amplification is significantly associated with BRCA1-mutant BLBC, where it is amplified at more than twice the frequency compared with BRCA1 wild-type BLBC (Prat et al. 2014; LA Baker, SA O’Toole,
C Selinger and A Swarbrick, unpublished observations). This indicates a genetic relationship between ID4 and $B R C A 1$ and a selective advantage for genetic dysregulation of the ID4 gene. Combined with the data presented above, we hypothesise that gain of ID4 is a mechanism through which the tumour suppressive function of BRCA1 can be inhibited.

\section{ID4 and BRCAness}

If ID4 regulates BRCA1, could this be important to the aetiology of BLBC? Could high ID4-expressing cancers identify patients with suppressed BRCA1 function?

The tumour suppressor BRCA1 is a crucial mediator of the DNA damage repair pathway (DDR). It repairs double-stranded DNA breaks and activates DNA damageinduced cell cycle checkpoints. In the absence of effective BRCA1 function, cells are unable to repair DNA, leading to the accumulation of mutations and the generation of genomic instability. Cells bypass normal checkpoint activation and progress aberrantly through the cell cycle (reviewed in Jasin 2002, Wu et al. 2010). BRCA1-mutant tumours demonstrate high genomic instability and increased frequency of rearrangements. The inability to effectively repair damaged DNA is characteristic of these tumours, a trait that is exploited with targeted therapies. Tumours with alterations to the BRCA1-homologous recombination (HR) pathway show clinical sensitivity to platinum-based chemotherapies (Tassone et al. 2009) and to targeted poly (ADP-ribose) polymerase (PARP) inhibitors (reviewed in Turner et al. 2004). PARP1 is a member of the DDR pathway that recruits and modifies nuclear proteins to respond to DNA damage (reviewed in Aly and Ganesan 2011). In the absence of effective PARP, cells are forced to repair damaged DNA through the BRCA1-mediated HR pathway. Hence, if PARP is inhibited in BRCA1-mutant breast cancers, DNA damage accumulates in the absence of effective repair mechanisms and cells undergo programmed cell death (Ashworth 2008). Hence, an important clinical opportunity exists for treatment of BRCA1-mutant tumours with available targeted therapeutics.

Evidence is emerging that some tumours can possess phenotypic similarities to BRCA1-mutant tumours without harbouring BRCA1 mutations. This trait has been termed BRCAness (Turner et al. 2004). Tumours exhibiting BRCAness have a similar frequency of mutational and copy number aberrations compared with BRCA1-mutant BLBC tumours, indicating a similar defect 
in HR. These tumours often possess epigenetic alterations to BRCA1 (including promoter hypermethylation and thus gene inactivation (Catteau et al. 1999, Esteller et al. 2000)) and alterations in other DNA damage repair pathway proteins and thus resemble BRCA1-mutant BLBCs (reviewed in Turner et al. 2004). In some cases, this phenotype may be explained by loss of members of the BRCA1-HR pathway including BARD1 (a BRCA1 protein interactor) (Sabatier et al. 2010), CHEK1 (cell cycle checkpoint mediator involved in mediating DNA repair), ATM (present at sites of DNA damage and recruits BRCA1), RAD51 (a functional marker of effective DDR in BLBC) (Lehmann et al. 2011), RAD17 (recruits MRE11RAD50-NBS1 complex to regulate the DDR) and RAD50 (Wang 2007, Alli et al. 2009, Lehmann et al. 2011).

It has been suggested that BRCAness may associate with sensitivity to therapies traditionally targeting BRCA1-mutant patients (Turner et al. 2004, Silver et al. 2010, Konstantinopoulos et al. 2010). Identification of a new subset of patients responsive to these therapies is an exciting possibility for BLBC patients who have no access to effective targeted therapies (Lips et al. 2013). As described above, ID4 is highly associated with BLBC, inhibits BRCA1 expression and is preferentially amplified in BRCA1-mutant BLBC. The expression and amplification status of ID4 in BRCA1 heterozygote patients in currently unknown; however, we suggest that ID4 overexpression and amplification is acquired in BRCA1 heterozygote mutant cancers or in wild-type patients to suppress remaining BRCA1 function, resulting in BRCA1-mutant and BRCAness phenotypes. These combined data offer new insights into a potentially clinically important role for ID4 in these cancers. Indeed, platinum and PARP inhibitor sensitivity screens on breast cancer cell lines shows that ID4 high-expressing cell lines have increased sensitivity to these therapies ((Lehmann et al. 2011) and Laura Baker unpublished data). We suggest that high ID4 expression may mark a subset of BLBC patients (BRCAness and BRCA1-mutant patients) who may benefit from therapies traditionally used exclusively in BRCA1-mutant cancers (platinum-based therapies and PARP inhibitors) (Beger et al. 2001, Turner et al. 2007, Alli et al. 2009).

\section{Conclusion}

Characterisation of the important pathways controlling mammary gland development, and identification of the cells prone to transformation is crucial to furthering our understanding of mammary tumorigenesis. ID4, a well-established transcriptional regulator, controls lineage commitment and terminal differentiation in the developing mammary gland. Loss of ID4 prevents normal ductal elongation and invasion of the mammary fat pad. Parallel to the role of ID4 in development, ID4 is emerging as a lineage commitment oncogene that is highly expressed and amplified in a subset of BLBC. Evidence suggests that BLBCs arise from luminal progenitor cells that often acquire mutation in or loss of BRCA1. The ensuing genomic instability may promote aberrant ID4 activity. These cells progress to form aggressive, poor prognosis ID4-positive tumours. ID4 positivity may mark a subset of BLBC patients who may respond to therapies traditionally used in BRCA1-mutant cancers including platinum-based chemotherapies and PARP inhibitors.

\section{Declaration of interest}

The authors declare that there is no conflict of interest that could be perceived as prejudicing the impartiality of this review.

\section{Funding}

The authors would like to acknowledge the following funding contributors who supported this work: NHMRC Project Grant APP1107671, John and Deborah McMurtrie, Australian Postgraduate Award (to L B and $\mathrm{H} \mathrm{H}$ ), the Castle Harlan Award (to $L B$ ), Boehringer Ingelheim Fonds Travel Award (to L B), the Beth Yarrow Award (to L B), and NHMRC Career Development Award (to A S)

\section{References}

Alli E, Sharma VB, Sunderesakumar P \& Ford JM 2009 Defective repair of oxidative dna damage in triple-negative breast cancer confers sensitivity to inhibition of poly (ADP-ribose) polymerase. Cancer Research 69 3589-3596. (doi:10.1158/0008-5472.CAN-08-4016)

Aly A \& Ganesan S 2011 BRCA1, PARP, and 53BP1: conditional synthetic lethality and synthetic viability. Journal of Molecular Cell Biology $\mathbf{3}$ 66-74. (doi:10.1093/jmcb/mjq055)

Ashworth A 2008 A synthetic lethal therapeutic approach: poly (ADP) ribose polymerase inhibitors for the treatment of cancers deficient in DNA double-strand break repair. Journal of Clinical Oncology 26 3785-3790. (doi:10.1200/JCO.2008.16.0812)

Asselin-Labat M-L, Sutherland KD, Barker H, Thomas R, Shackleton M, Forrest NC, Hartley L, Robb L, Grosveld FG \& van der Wees J 2007 Gata-3 is an essential regulator of mammary-gland morphogenesis and luminal-cell differentiation. Nature Cell Biology 9 201-209. (doi:10.1038/ncb1530)

Badve S, Dabbs DJ, Schnitt SJ, Baehner FL, Decker T, Eusebi V, Fox SB, Ichihara S, Jacquemier J \& Lakhani SR 2011 Basal-like and triplenegative breast cancers: a critical review with an emphasis on the implications for pathologists and oncologists. Modern Pathology 24 157-167. (doi:10.1038/modpathol.2010.200)

Bai L \& Rohrschneider LR 2010 s-SHIP promoter expression marks activated stem cells in developing mouse mammary tissue. Genes \& Development 24 1882-1892. (doi:10.1101/gad.1932810)

Barker N, Ridgway RA, van Es JH, van de Wetering M, Begthel H, van den Born M, Danenberg E, Clarke AR, Sansom OJ \& Clevers H 2009

Published by Bioscientifica Ltc 
Crypt stem cells as the cells-of-origin of intestinal cancer. Nature $\mathbf{4 5 7}$ 608-611. (doi:10.1038/nature07602)

Beger C, Pierce LN, Krüger M, Marcusson EG, Robbins JM, Welcsh P, Welch PJ, Welte K, King M-C \& Barber JR 2001 Identification of Id4 as a regulator of BRCA1 expression by using a ribozyme-library-based inverse genomics approach. PNAS 98 130-135. (doi:10.1073/ pnas.98.1.130)

Bertheau P, Lehmann-Che J, Varna M, Dumay A, Poirot B, Porcher R, Turpin E, Plassa L-F, De Roquancourt A \& Bourstyn E 2013 p53 in breast cancer subtypes and new insights into response to chemotherapy. Breast 22 S27-S29. (doi:10.1016/j.breast.2013.07.005)

Best SA, Hutt KJ, Fu NY, Vaillant F, Liew SH, Hartley L, Scott CL, Lindeman GJ \& Visvader JE 2014 Dual roles for Id4 in the regulation of estrogen signaling in the mammary gland and ovary. Development 141 3159-3164. (doi:10.1242/dev.108498)

Blanpain C \& Fuchs E 2014 Plasticity of epithelial stem cells in tissue regeneration. Science 344 1242281. (doi:10.1126/science.1242281)

Bouras T, Pal B, Vaillant F, Harburg G, Asselin-Labat M-L, Oakes SR, Lindeman GJ \& Visvader JE 2008 Notch signaling regulates mammary stem cell function and luminal cell-fate commitment. Cell Stem Cell 3 429-441. (doi:10.1016/j.stem.2008.08.001)

Branham M, Marzese D, Laurito S, Gago F, Orozco J, Tello O, Vargas-Roig L \& Roque M 2012 Methylation profile of triplenegative breast carcinomas. Oncogenesis 1 e17. (doi:10.1038/ oncsis.2012.17)

Cancer Genome Atlas Network 2012 Comprehensive molecular portraits of human breast tumours. Nature 490 61-70.

Carey JP, Asirvatham AJ, Galm O, Ghogomu TA \& Chaudhary J 2009 Inhibitor of differentiation 4 (Id4) is a potential tumor suppressor in prostate cancer. BMC Cancer 9 173. (doi:10.1186/1471-2407-9-173)

Carr JR, Kiefer MM, Park HJ, Li J, Wang Z, Fontanarosa J, Dewaal D, Kopanja D, Benevolenskaya EV \& Guzman G 2012 FoxM1 regulates mammary luminal cell fate. Cell Reports 1 715-729. (doi:10.1016/j. celrep.2012.05.005)

Catteau A, Harris WH, Xu C-F \& Solomon E 1999 Methylation of the BRCA1 promoter region in sporadic breast and ovarian cancer: correlation with disease characteristics. Oncogene 18 1957-1965. (doi:10.1038/sj.onc.1202509)

Chaffer CL, Marjanovic ND, Lee T, Bell G, Kleer CG, Reinhardt F, D'Alessio AC, Young RA \& Weinberg RA 2013 Poised chromatin at the ZEB1 promoter enables breast cancer cell plasticity and enhances tumorigenicity. Cell 154 61-74. (doi:10.1016/j.cell.2013.06.005)

Chen CH, Kuo SC, Huang LJ, Hsu MH \& Lung FDT 2010 Affinity of synthetic peptide fragments of MyoD for Id1 protein and their biological effects in several cancer cells. Journal of Peptide Science $\mathbf{1 6}$ 231-241. (doi:10.1002/psc.1216)

Crippa E, Lusa L, De Cecco L, Marchesi E, Calin GA, Radice P, Manoukian S, Peissel B, Daidone MG \& Gariboldi M 2014 miR-342 regulates BRCA1 expression through modulation of ID4 in breast cancer. PLoS ONE 9 e87039. (doi:10.1371/journal.pone.0087039)

De Candia P, Akram M, Benezra R \& Brogi E 2006 Id4 messenger RNA and estrogen receptor expression: inverse correlation in human normal breast epithelium and carcinoma. Human Pathology $\mathbf{3 7}$ 1032-1041. (doi:10.1016/j.humpath.2006.03.004)

Dong J, Huang S, Caikovski M, Ji S, Mcgrath A, Custorio MG, Creighton CJ, Maliakkal P, Bogoslovskaia E \& Du Z 2011 ID4 regulates mammary gland development by suppressing p38MAPK activity. Development 138 5247-5256. (doi:10.1242/dev.069203)

Esteller M, Silva JM, Dominguez G, Bonilla F, Matias-Guiu X, Lerma E, Bussaglia E, Prat J, Harkes IC \& Repasky EA 2000 Promoter hypermethylation and BRCA1 inactivation in sporadic breast and ovarian tumors. Journal of the National Cancer Institute 92 564-569. (doi:10.1093/jnci/92.7.564)

Fan S, Wang J-A, Yuan R, Ma Y, Meng Q, Erdos M, Pestell R, Yuan F, Auborn K \& Goldberg I 1999 BRCA1 inhibition of estrogen receptor signaling in transfected cells. Science 284 1354-1356. (doi:10.1126/ science.284.5418.1354)

Feng Y, Manka D, Wagner K-U \& Khan SA 2007 Estrogen receptor- $\alpha$ expression in the mammary epithelium is required for ductal and alveolar morphogenesis in mice. PNAS 104 14718-14723. (doi:10.1073/pnas.0706933104)

Fernandez-Valdivia R, Mukherjee A, Creighton CJ, Buser AC, Demayo FJ, Edwards DP \& Lydon JP 2008 Transcriptional response of the murine mammary gland to acute progesterone exposure. Endocrinology 149 6236-6250. (doi:10.1210/en.2008-0768)

Fontemaggi G, Dell'Orso S, Trisciuoglio D, Shay T, Melucci E, Fazi F Terrenato I, Mottolese M, Muti P \& Domany E 2009 The execution of the transcriptional axis mutant p53, E2F1 and ID4 promotes tumor neo-angiogenesis. Nature Structural \& Molecular Biology 16 1086-1093. (doi:10.1038/nsmb.1669)

Furuta S, Jiang X, Gu B, Cheng E, Chen P-L \& Lee W-H 2005 Depletion of BRCA1 impairs differentiation but enhances proliferation of mammary epithelial cells. PNAS 102 9176-9181. (doi:10.1073/ pnas.0503793102)

Garraway LA \& Sellers WR 2006 Lineage dependency and lineagesurvival oncogenes in human cancer. Nature Reviews Cancer 6 593-602. (doi:10.1038/nrc1947)

Gry M, Rimini R, Stromberg S, Asplund A, Ponten F, Uhlen M \& Nilsson P 2009 Correlations between RNA and protein expression profiles in 23 human cell lines. BMC Genomics 10365. (doi:10.1186/1471-2164-10-365)

Gusterson BA, Ross DT, Heath VJ \& Stein T 2005 Basal cytokeratins and their relationship to the cellular origin and functional classification of breast cancer. Breast Cancer Research 7 143-148. (doi:10.1186/bcr1041)

Hanahan D \& Weinberg RA 2011 Hallmarks of cancer: the next generation. Cell 144 646-674. (doi:10.1016/j.cell.2011.02.013)

Jasin M 2002 Homologous repair of DNA damage and tumorigenesis: the BRCA connection. Oncogene 21 8981-8993. (doi:10.1038/sj. onc.1206176)

Junankar S, Baker LA, Roden DL, Nair R, Elsworth B, Gallego-Ortega D, Lacaze P, Cazet A, Nikolic I \& Teo WS 2015 ID4 controls mammary stem cells and marks breast cancers with a stem cell-like phenotype. Nature Communications 6 6548. (doi:10.1038/ncomms7548)

Khan SA, Rogers MA, Khurana KK, Meguid MM \& Numann PJ 1998 Estrogen receptor expression in benign breast epithelium and breast cancer risk. Journal of the National Cancer Institute 90 37-42. (doi:10.1093/jnci/90.1.37)

Konstantinopoulos PA, Spentzos D, Karlan BY, Taniguchi T, Fountzilas E, Francoeur N, Levine DA \& Cannistra SA 2010 Gene expression profile of BRCAness that correlates with responsiveness to chemotherapy and with outcome in patients with epithelial ovarian cancer. Journal of Clinical Oncology 28 3555-3561. (doi:10.1200/ JCO.2009.27.5719)

Korach KS, Couse JF, Curtis SW, Washburn TF, Lindzey J, Kimbro KS, Eddy EM, Migliaccio S, Snedeker SM \& Lubahn DB 1995 Estrogen receptor gene disruption: molecular characterization and experimental and clinical phenotypes. Recent Progress in Hormone Research 51 159-186.

Korlimarla A, Prabhu JS, Remacle J, Rajarajan S, Raja U, Anupama C, Srinath B, Manjunath S, Gopinath K \& Correa M 2016 Identification of BRCA1 deficiency using multi-analyte estimation of BRCA1 and its repressors in FFPE tumor samples from patients with triple negative breast cancer. PLOS ONE 11 e0153113. (doi:10.1371/journal. pone.0153113)

Kouros-Mehr H, Slorach EM, Sternlicht MD \& Werb Z 2006 GATA-3 maintains the differentiation of the luminal cell fate in the mammary gland. Cell 127 1041-1055. (doi:10.1016/j. cell.2006.09.048)

Lakhani SR, Reis-Filho JS, Fulford L, Penault-Llorca F, van der Vijver M, Parry S, Bishop T, Benitez J, Rivas C \& Bignon Y-J 2005 Prediction of http://erc.endocrinology-journals.org

DOI: $10.1530 /$ ERC-16-0196
(C) 2016 Society for Endocrinology Printed in Great Britain
Published by Bioscientifica Ltd 
BRCA1 status in patients with breast cancer using estrogen receptor and basal phenotype. Clinical Cancer Research 11 5175-5180. (doi:10.1158/1078-0432.CCR-04-2424)

Lasorella A, Benezra R \& Iavarone A 2014 The ID proteins: master regulators of cancer stem cells and tumour aggressiveness. Nature Reviews Cancer 14 77-91. (doi:10.1038/nrc3638)

Lehmann BD, Bauer JA, Chen X, Sanders ME, Chakravarthy AB, Shyr Y \& Pietenpol JA 2011 Identification of human triple-negative breast cancer subtypes and preclinical models for selection of targeted therapies. Journal of Clinical Investigation 121 2750. (doi:10.1172/ JCI45014)

Li N, Singh S, Cherukuri P, Li H, Yuan Z, Ellisen LW, Wang B, Robbins D \& Direnzo J 2008 Reciprocal intraepithelial interactions between TP63 and hedgehog signaling regulate quiescence and activation of progenitor elaboration by mammary stem cells. Stem Cells $\mathbf{2 6}$ 1253-1264. (doi:10.1634/stemcells.2007-0691)

Lim E, Vaillant F, Wu D, Forrest NC, Pal B, Hart AH, Asselin-Labat M-L, Gyorki DE, Ward T \& Partanen A 2009 Aberrant luminal progenitors as the candidate target population for basal tumor development in BRCA1 mutation carriers. Nature Medicine 15 907-913. (doi:10.1038/ $\mathrm{nm} .2000)$

Lim E, Wu D, Pal B, Bouras T, Asselin-Labat M-L, Vaillant F, Yagita H, Lindeman GJ, Smyth GK \& Visvader JE 2010 Transcriptome analyses of mouse and human mammary cell subpopulations reveal multiple conserved genes and pathways. Breast Cancer Research 12 1-14. (doi:10.1186/bcr2560)

Lindvall C, Evans NC, Zylstra CR, Li Y, Alexander CM \& Williams BO 2006 The Wnt signaling receptor Lrp5 is required for mammary ductal stem cell activity and Wnt1-induced tumorigenesis. Journal of Biological Chemistry 281 35081-35087. (doi:10.1074/jbc. M607571200)

Lips E, Mulder L, Oonk A, van der Kolk L, Hogervorst F, Imholz A Wesseling J, Rodenhuis S \& Nederlof P 2013 Triple-negative breast cancer: BRCAness and concordance of clinical features with BRCA1mutation carriers. British Journal of Cancer 108 2172-2177. (doi:10.1038/bjc.2013.144)

Liu S, Ginestier C, Charafe-Jauffret E, Foco H, Kleer CG, Merajver SD, Dontu G \& Wicha MS 2008 BRCA1 regulates human mammary stem/progenitor cell fate. PNAS 105 1680-1685. (doi:10.1073/ pnas.0711613105)

Lumachi F, Santeufemia DA \& Basso SM 2015 Current medical treatment of estrogen receptor-positive breast cancer. World Journal of Biological Chemistry 6 231. (doi:10.4331/wjbc.v6.i3.231)

Mallepell S, Krust A, Chambon P \& Brisken C 2006 Paracrine signaling through the epithelial estrogen receptor $\alpha$ is required for proliferation and morphogenesis in the mammary gland. PNAS 103 2196-2201. (doi:10.1073/pnas.0510974103)

Mavaddat N, Antoniou AC, Easton DF \& Garcia-Closas M 2010 Genetic susceptibility to breast cancer. Molecular Oncology 4 174-191. (doi:10.1016/j.molonc.2010.04.011)

Miki Y, Swensen J, Shattuck-Eidens D, Futreal PA, Harshman K, Tavtigian S, Liu Q, Cochran C, Bennett LM \& Ding W 1994 A strong candidate for the breast and ovarian cancer susceptibility gene BRCA1. Science 266 66-71. (doi:10.1126/science.7545954)

Molyneux G, Geyer FC, Magnay F-A, Mccarthy A, Kendrick H, Natrajan R, Mackay A, Grigoriadis A, Tutt A \& Ashworth A 2010 BRCA1 basal-like breast cancers originate from luminal epithelial progenitors and not from basal stem cells. Cell Stem Cell 7 403-417. (doi:10.1016/j.stem.2010.07.010)

Mullan P, Quinn J \& Harkin D 2006 The role of BRCA1 in transcriptional regulation and cell cycle control. Oncogene $\mathbf{2 5}$ 5854-5863. (doi:10.1038/sj.onc.1209872)

Nair R, Teo WS, Mittal V \& Swarbrick A 2014 ID proteins regulate diverse aspects of cancer progression and provide novel therapeutic opportunities. Molecular Therapy 22 1407-1415. (doi:10.1038/ $\mathrm{mt}$.2014.83)
Natrajan R, Weigelt B, Mackay A, Geyer FC, Grigoriadis A, Tan DS, Jones C, Lord CJ, Vatcheva R \& Rodriguez-Pinilla SM 2010 An integrative genomic and transcriptomic analysis reveals molecular pathways and networks regulated by copy number aberrations in basal-like, HER2 and luminal cancers. Breast Cancer Research and Treatment 121 575-589. (doi:10.1007/s10549-009. 0501-3)

Oakes SR, Naylor MJ, Asselin-Labat M-L, Blazek KD, Gardiner-Garden M, Hilton HN, Kazlauskas M, Pritchard MA, Chodosh LA \& Pfeffer PL 2008 The Ets transcription factor Elf5 specifies mammary alveolar cell fate. Genes \& Development 22 581-586. (doi:10.1101/ gad.1614608)

Perou CM, Sørlie T, Eisen MB, van de Rijn M, Jeffrey SS, Rees CA, Pollack JR, Ross DT, Johnsen H \& Akslen LA 2000 Molecular portraits of human breast tumours. Nature 406 747-752. (doi:10.1038/35021093)

Prat A \& Perou CM 2011 Deconstructing the molecular portraits of breast cancer. Molecular Oncology 5 5-23. (doi:10.1016/j. molonc.2010.11.003)

Prat A, Adamo B, Cheang MC, Anders CK, Carey LA \& Perou CM 2013 Molecular characterization of basal-like and non-basal-like triplenegative breast cancer. Oncologist 18 123-133. (doi:10.1634/ theoncologist.2012-0397)

Prat A, Cruz C, Hoadley KA, Díez O, Perou CM \& Balmaña J 2014 Molecular features of the basal-like breast cancer subtype based on BRCA1 mutation status. Breast Cancer Research and Treatment 147 185-191. (doi:10.1007/s10549-014-3056-x)

Rakha EA, Reis-Filho JS \& Ellis IO 2008 Basal-like breast cancer: a critical review. Journal of Clinical Oncology 26 2568-2581. (doi:10.1200/ JCO.2007.13.1748)

Rios AC, Fu NY, Lindeman GJ \& Visvader JE 2014 In situ identification of bipotent stem cells in the mammary gland. Nature 506 322-327. (doi:10.1038/nature12948)

Roldán G, Delgado L \& Musé IM 2006 Tumoral expression of BRCA1, estrogen receptor alpha and ID4 protein in patients with sporadic breast cancer. Cancer Biology \& Therapy 5 505-510. (doi:10.4161/ cbt.5.5.2597)

Sabatier R, Adélaïde J, Finetti P, Ferrari A, Huiart L, Sobol H, Chaffanet M, Birnbaum D \& Bertucci F 2010 BARD1 homozygous deletion, a possible alternative to BRCA1 mutation in basal breast cancer. Genes, Chromosomes and Cancer 49 1143-1151. (doi:10.1002/ gcc.20822)

Shackleton M, Vaillant F, Simpson KJ, Stingl J, Smyth GK, AsselinLabat M-L, Wu L, Lindeman GJ \& Visvader JE 2006 Generation of a functional mammary gland from a single stem cell. Nature $\mathbf{4 3 9}$ 84-88. (doi:10.1038/nature04372)

Shan L, Yu M, Qiu C \& Snyderwine EG 2003 Id4 regulates mammary epithelial cell growth and differentiation and is overexpressed in rat mammary gland carcinomas. American Journal of Pathology 163 2495-2502. (doi:10.1016/S0002-9440(10)63604-8)

Sharma P, Chinaranagari S, Patel D, Carey J \& Chaudhary J 2012 Epigenetic inactivation of inhibitor of differentiation 4 (Id4) correlates with prostate cancer. Cancer Medicine 1 176-186. (doi:10.1002/cam4.16)

Sharma P, Knowell AE, Chinaranagari S, Komaragiri S, Nagappan P, Patel D, Havrda MC \& Chaudhary J 2013 Id4 deficiency attenuates prostate development and promotes PIN-like lesions by regulating androgen receptor activity and expression of NKX3. 1 and PTEN. Molecular Cancer 12 1. (doi:10.1186/1476-4598-12-1)

Sharma P, Chinaranagari S \& Chaudhary J 2015 Inhibitor of differentiation 4 (ID4) acts as an inhibitor of ID-1,-2 and-3 and promotes basic helix loop helix (bHLH) E47 DNA binding and transcriptional activity. Biochimie 112 139-150. (doi:10.1016/j. biochi.2015.03.006)

Silver DP, Richardson AL, Eklund AC, Wang ZC, Szallasi Z, Li Q, Juul N, Leong C-O, Calogrias D \& Buraimoh A 2010 Efficacy of neoadjuvant 
Cisplatin in triple-negative breast cancer. Journal of Clinical Oncology 28 1145-1153. (doi:10.1200/JCO.2009.22.4725)

Sørlie T, Perou CM, Tibshirani R, Aas T, Geisler S, Johnsen H, Hastie T, Eisen MB, van de Rijn M \& Jeffrey SS 2001 Gene expression patterns of breast carcinomas distinguish tumor subclasses with clinical implications. PNAS 98 10869-10874. (doi:10.1073/pnas.191367098)

Stingl J, Eirew P, Ricketson I, Shackleton M, Vaillant F, Choi D, Li HI \& Eaves CJ 2006 Purification and unique properties of mammary epithelial stem cells. Nature 439 993-997. (doi:10.1038/ nature04496)

Tassone P, Di Martino MT, Ventura M, Pietragalla A, Cucinotto I, Calimeri T, Neri P, Caraglia M, Tagliaferri P \& Bulotta A 2009 Loss of BRCA1 function increases the antitumor activity of cisplatin against human breast cancer xenografts in vivo. Cancer Biology \& Therapy $\mathbf{8}$ 648-653. (doi:10.4161/cbt.8.7.7968)

Thike AA, Tan PH, Ikeda M \& Iqbal J 2015 Increased ID4 expression, accompanied by mutant p53 accumulation and loss of BRCA1/2 proteins in triple-negative breast cancer, adversely affects survival. Histopathology 68 702-712. (doi:10.1111/his.12801)

Turner N, Tutt A \& Ashworth A 2004 Hallmarks of 'BRCAness' in sporadic cancers. Nature Reviews Cancer 4 814-819. (doi:10.1038/ nrc1457)

Turner N, Reis-Filho J, Russell A, Springall R, Ryder K, Steele D, Savage K, Gillett C, Schmitt F \& Ashworth A 2007 BRCA1 dysfunction in sporadic basal-like breast cancer. Oncogene 26 2126-2132. (doi:10.1038/sj.onc.1210014)

Valenti F, Ganci F, Fontemaggi G, Sacconi A, Strano S, Blandino G \& Di Agostino S 2015 Gain of function mutant p53 proteins cooperate with E2F4 to transcriptionally downregulate RAD17 and BRCA1 gene expression. Oncotarget 6 5547-5566. (doi:10.18632/oncotarget.2587)

van Keymeulen A, Rocha AS, Ousset M, Beck B, Bouvencourt G, Rock J, Sharma N, Dekoninck S \& Blanpain C 2011 Distinct stem cells contribute to mammary gland development and maintenance. Nature 479 189-193. (doi:10.1038/nature10573)

Visvader JE 2009 Keeping abreast of the mammary epithelial hierarchy and breast tumorigenesis. Genes \& Development 23 2563-2577. (doi:10.1101/gad.1849509)

Wang W 2007 Emergence of a DNA-damage response network consisting of Fanconi anaemia and BRCA proteins. Nature Reviews Genetics 8 735-748. (doi:10.1038/nrg2159)

Wang D, Cai C, Dong X, Yu QC, Zhang X-O, Yang L \& Zeng YA 2015 Identification of multipotent mammary stem cells by protein $\mathrm{C}$ receptor expression. Nature $\mathbf{5 1 7}$ 81-84. (doi:10.1038/nature13851)

Watson CJ \& Khaled WT 2008 Mammary development in the embryo and adult: a journey of morphogenesis and commitment. Development 135 995-1003. (doi:10.1242/dev.005439)

Welcsh PL, Lee MK, Gonzalez-Hernandez RM, Black DJ, Mahadevappa M, Swisher EM, Warrington JA \& King M-C 2002 BRCA1 transcriptionally regulates genes involved in breast tumorigenesis. PNAS 99 7560-7565. (doi:10.1073/pnas.062181799)

Wen YH, Ho A, Patil S, Akram M, Catalano J, Eaton A, Norton L, Benezra R \& Brogi E 2012 Id4 protein is highly expressed in triplenegative breast carcinomas: possible implications for BRCA1 downregulation. Breast Cancer Research and Treatment 135 93-102. (doi:10.1007/s10549-012-2070-0)

Williams JM \& Daniel CW 1983 Mammary ductal elongation: differentiation of myoepithelium and basal lamina during branching morphogenesis. Developmental Biology 97 274-290. (doi:10.1016/0012-1606(83)90086-6)

Wu J, Lu L-Y \& Yu X 2010 The role of BRCA1 in DNA damage response. Protein \& Cell 1 117-123. (doi:10.1007/s13238-010-0010-5)

Zeng YA \& Nusse R 2010 Wnt proteins are self-renewal factors for mammary stem cells and promote their long-term expansion in culture. Cell Stem Cell 6 568-577. (doi:10.1016/j.stem.2010.03.020)

Received in final form 20 June 2016

Accepted 13 July 2016

Accepted Preprint published online 13 July 2016
C 2016 Society for Endocrinology Printed in Great Britain 